\title{
The Distribution and Formation of Penicillinase in a Bacterial Population of Bacillus licheniformis
}

\author{
By J. F. COLLINS \\ National Institute for Medical Research, The Ridgeway, \\ Mill Hill, London, N.W. 7
}

(Received 8 May 1963)

\begin{abstract}
SUMMARY
The distributions of penicillinase in populations of uninduced, induced and constitutive cultures of Bacillus licheniformis strains 749 and $749 / \mathrm{C}$ each showed a large positive skew. Analysis of the enzyme distribution in the uninduced population as a Poisson distribution showed that penicillinase molecules were produced not as independent random events, but in clusters containing 1100 molecules. There were $0-4$ (average $0 \cdot 85$ ) clusters/ organism. The fundamental random event resulting in the formation of a cluster of penicillinase molecules may be the formation of one enzymeforming site capable of producing $\mathbf{1 1 0 0}$ such molecules. Analysis of the enzyme distribution in the constitutive population showed that in this case penicillinase was produced in groups of 55,000 molecules, or fifty of the clusters of penicillinase found in the organisms of the uninduced population. This may be the number of enzyme-forming sites made by a constitutive penicillinase gene during the period between its formation and replication. Analysis of the enzyme distribution in the induced population showed that the organisms did not respond equally after induction, but all organisms probably increased their rates of penicillinase synthesis. Enzyme partition can be highly asymmetric when an organism divides; the enzyme molecules do not appear to be able to diffuse freely within the cell cytoplasm, but may be associated with some structurally rigid material in the organisms.
\end{abstract}

\section{INTRODUCTION}

The formation of a particular enzyme by a bacterial cell depends in the first place upon the necessary genetic information being present in the cell. Other factors then determine the amount of the enzyme actually produced. These factors will include the presence or absence of any agent (such as an inducer or repressor) which specifically affects the formation of the particular enzyme, and local environmental factors which affect the availability of the intermediates necessary for the formation of protein molecules, or which affect the stability of any of the compounds involved. Since these factors may vary from cell to cell in a single culture, the behaviour of genetically identical cells need not necessarily be the same, though the possible variation cannot be easily predicted. From the nature of the variation in enzyme content in individual bacteria certain deductions may be made about the nature and significance of the various factors which control specific enzyme synthesis and which could not be obtained from observations of large bacterial populations.

The behaviour within a bacterial population has been studied by indirect methods in the case of $\beta$-galactosidase in Escherichia coli. Benzer (1953) showed that 
gratuitous induction of this enzyme proceeded in an apparently homogeneous fashion throughout the bacterial population, but non-gratuitous induction gave a heterogeneous response. Novick \& Weiner (1957) showed that gratuitous induction at low inducer concentrations gave a heterogeneous response; in this system, however, the induction of $\beta$-galactosidase is complicated by the presence in the normal strains of $\boldsymbol{E}$. coli studied of a galactoside-permease which concentrates galactosides (the inducers) inside the cell, and which is itself inducible. The homogeneous and heterogeneous formation of $\beta$-galactosidase in $E$. coli appears to reflect the distribution of the permease within the population (Cohn \& Horibata, 1959a, $b$ ). The indirect methods used in the study of this system do not reveal other details of the enzyme distribution among individuals of the population.

The microspectrophotometric method for the assay of penicillinase described in the paper by Collins, Mason \& Perkins (1964) enables the amount of this enzyme in a single bacterium to be estimated directly with sufficient sensitivity to detect less than 50 molecules of penicillinase, assuming (as appears reasonable from preliminary findings with purified penicillinase from Bacillus licheniformis strain 749/c; Dr M. R. Pollock, private communication) the molecular activity of the penicillinase studied to be similar to that of the penicillinase of Bacillus cereus strain 569 (Kogut, Pollock \& Tridgell, 1956).

The distribution of the penicillinase has now been studied in populations of Bacillus licheniformis strain $\mathbf{7 4 9}$ (Kushner, 1960) in which it is an inducible enzyme, and in a mutant strain derived from this in which penicillinase is a constitutive enzyme. Three populations have been studied to examine the distribution of penicillinase amongst organisms $(a)$ uninduced, $(b)$ after growth for one generation in the presence of an inducer, $(c)$ of the mutant constitutive strain.

\section{METHODS}

Organisms. Bacillus licheniformis strain 749 (Kushner, 1960) and a mutant strain constitutive for penicillinase (B. licheniformis strain $749 / \mathrm{c}$ ) were used in the experiments. The mutant strain was isolated by Dr M. R. Pollock from $B$. licheniformis strain 749 spores by a method based on that of Novick (1963). Both strains were maintained as spore suspensions in distilled water.

Growth media, etc. For the production of spores, 'S' broth (Pollock \& Perret, 1951) cultures were shaken at $35^{\circ}$ for 10 days. The spores were washed three times with distilled water and then resuspended in distilled water at a concentration of $3 \times 10^{8}$ viable spores $/ \mathrm{ml}$. Viable counts were made on diluted spore suspensions which were poured in $3 \mathrm{ml}$. molten $3 \%$ agar-Hedley Wright broth (Wright, 1933) on to the same solid medium, and incubated for $18 \mathrm{hr}$ at $35^{\circ}$.

For liquid cultures casein hydrolysate medium (Kogut et al. 1956) was used without citrate, and with the addition of $0.1 \%(\mathrm{v} / \mathrm{v})$ ' salts' solution (Collins \& Kornberg, 1960) which contains a variety of metal ions. This was called CHS medium. Cultures (20 ml. CHS medium in a $250 \mathrm{ml}$. flask) were inoculated with $3 \times 10^{6}$ spores/ ml., and shaken on a reciprocating shaker $\left(86\right.$ cyc. $/$ min.; 1 in. throw) at $35^{\circ}$. After $12 \mathrm{hr}$ the culture contained the equivalent of $0.25 \mathrm{mg}$. dry wt. bacteria $/ \mathrm{ml}$., and was still growing exponentially. Fresh warm medium $(20 \mathrm{ml}$. CHS medium in a $250 \mathrm{ml}$. flask) was inoculated from this culture to a concentration of $0.07 \mathrm{mg}$. dry 
wt. bacteria/ml. and transferred to another part of the reciprocating shaker where the throw was $3 \cdot 5$ in. Growth was measured turbidimetrically. The culture was allowed to grow to a density equivalent to $\mathbf{0 . 2} \mathrm{mg}$. dry wt./ml. before harvesting. For the investigation of cell-bound enzyme, the organisms were harvested by filtering the culture through a cellulose acetate membrane (' Oxoid'). The organisms on the filter were washed with a small volume of cold saline to remove traces of soluble enzyme, and were resuspended in saline to a concentration of $10^{10}$ organisms/ ml. (equivalent to about $10 \mathrm{mg}$. dry wt. $/ \mathrm{ml}$.). Kept at $0^{\circ}$, the organisms held the bound enzyme firmly, losing about $1 \%$ per hr into the saline. (At room temperature about $40 \%$ was lost in $1 \mathrm{hr}$.)

Determination of the mean residence time of penicillinase molecules in organisms. In an exponentially growing culture, the formation of free penicillinase lags behind the total penicillinase production because of the period during which the enzyme stays associated with the bacilli. The mean residence time is equivalent to the time that would be required for the rate of release, increasing exponentially with the same growth constant as the culture, to equal the present rate of formation. This may be expressed as

$$
\frac{\mathrm{d} F}{\mathrm{~d} t} 2^{r / t}=\frac{\mathrm{d} E}{\mathrm{~d} t}
$$

where $\mathrm{d} F / \mathrm{d} t=$ rate of formation of free penicillinase, $\mathrm{d} E / \mathrm{d} t=$ rate of formation of total penicillinase, $r=$ mean residence time, $t=$ doubling time of culture, and hence $r / t=$ mean residence time expressed in doubling times of the culture. In order to measure the ratio of these rates of formation, steady-state growth experiments were performed in a 'turbidostat' so that observations could be made over prolonged periods of exponential growth. In the steady state, penicillinase was being synthesized by the bacteria in the culture vessel as fast as it was being washed out with the medium, i.e. at a rate proportional to $(a)$ the total concentration of penicillinase present, and $(b)$ the flow rate through the vessel. Similarly, free penicillinase was also being formed as fast as it was washed out, i.e. at a rate proportional to $(a)$ the concentration of free penicillinase in the medium, and $(b)$ the flow rate through the vessel. The rates of formation of total and free penicillinase could thus be compared as the ratio of the total and free enzyme concentrations in the steady state, and hence the mean residence time could be calculated. In the steady state,

$$
\frac{\mathrm{d} E}{\mathrm{~d} t}=E \frac{\mathrm{d} v}{\mathrm{~d} t} \text { and } \quad \frac{\mathrm{d} F}{\mathrm{~d} t}=F \frac{\mathrm{d} v}{\mathrm{~d} t},
$$

where $\mathrm{d} \boldsymbol{E} / \mathrm{d} t=$ the rate of formation of penicillinase, $\mathrm{d} \boldsymbol{F} / \mathrm{d} t=$ the rate of release of penicillinase into the medium, $E=$ total penicillinase concentration, $F=$ free penicillinase concentration and $\mathrm{d} v / \mathrm{d} t=$ flow rate through the vessel.

Hence

$$
\frac{1}{E} \frac{\mathrm{d} E}{\mathrm{~d} t}=\frac{1}{F} \frac{\mathrm{d} F}{\mathrm{~d} t}
$$

and from equation (1)

$$
2^{\prime \prime t}=E / F \text {. }
$$

Steady-state grozoth experiments. Exponentially growing cultures of Bacillus licheniformis strains 749 and $749 / \mathrm{c}$ were maintained in steady multiplication by 
pumping fresh CHS medium into aerated cultures, and pumping out the culture at a balancing rate. The pumping rates were adjusted manually to maintain a constant optical density and a constant culture volume. After growth for 4-5 hr the penicillinase activity of the whole culture and that bound to the bacteria were measured. Several samples were taken in each experiment and each experiment was repeated several times. In this manner the steady-state distribution of penicillinase between the bacteria and the medium was measured for the basal and for the induced enzyme in $B$. licheniformis strain $\mathbf{7 4 9}$, and for the constitutive enzyme in $\boldsymbol{B}$. licheniformis strain $749 / \mathrm{c}$. In the case of the induced enzyme, the culture was grown in the presence of 1 or $5 \mu \mathrm{g}$. cephalosporin C (Glaxo Laboratories Ltd.)/ml., with the cephalosporin added to the growing culture in the flask and also pumped in at this concentration in fresh medium.

Induction experiments. For routine induction experiments in bulk cultures in shaken flasks, cultures containing the equivalent of $0.1 \mathrm{mg}$. dry wt. bacteria $/ \mathrm{ml}$. were induced with cephalosporin $\mathrm{C}$ at $5 \mu \mathrm{g} . / \mathrm{ml}$; this concentration produced no change in the growth rate. The organisms were harvested and washed when the culture contained the equivalent of $0 \cdot 2 \mathrm{mg}$. dry wt. bacteria $/ \mathrm{ml}$.

Large-scale penicillinase assays. The iodometric assay of Perret (1954) was used for the assays of penicillinase in whole cultures, suspensions of washed organisms or in cell-free culture media.

Penicillinase microassay. The basis of the penicillinase microassay was the observation of the rate of the enzymic reaction in a microdrop containing a single organism (Collins, 1962). The method of preparing the stable microdrops, the basic assay mixture and the microphotometer have been described in the previous paper (Collins et al. 1964). The reaction mixture for the estimation of the basal enzyme contained: $2.0 \mathrm{ml} .4 \%(\mathrm{w} / \mathrm{v})$ bromocresol purple (G. T. Gurr Ltd.; adjusted to pH $6 \cdot 15$ with sodium hydroxide); $1 \cdot 0 \mathrm{ml} .0 \cdot 2 \mathrm{M}-\mathrm{K}_{2} \mathrm{HPO}_{4}, 0 \cdot 4 \mathrm{ml}$. benzylpenicillin solution (containing $2 \times 10^{5} \mathrm{i} . \mathrm{u} . / \mathrm{ml}$. dissolved in saline); $0 \cdot 2 \mathrm{ml}$. saline. The final $\mathrm{pH}$ value of the mixture was about $7 \cdot 4$. For each experiment $0.18 \mathrm{ml}$. of this reaction mixture was mixed with $0.02 \mathrm{ml}$. washed bacterial suspension, and drops were prepared by spraying the mixture through a fine capillary tube into a drop of silicone oil on a water-repellent coverslip. This was covered with a second waterrepellent coverslip. The selection of a drop of suitable diameter $(7-10 \mu)$ containing a single organism was made by eye, using white light illumination and with the condenser of the microscope racked down somewhat from the normal position. Drops could then be searched carefully for organisms, and when necessary a purple filter could be used to decrease the contrast between the purple drop and the surrounding area. The sequence of operations after the drop was selected is described in the previous paper (Collins et al. 1964). The calculation of the total amount of enzyme in a drop was made from the recorded output from the photometer, which gives the total incident light, the transmitted light and the rate of change of transmitted light and from the diameter of the drop (Collins et al. 1964).

The reaction mixture was modified when organisms containing large amounts of penicillinase were tested; in order to obtain satisfactory records from the microphotometer it was necessary to slow the reaction, while maintaining proportionality between rate and amount of enzyme. This was achieved by adding 6-(2,6-dimethoxybenzamido)-penicillanic acid ('Methicillin'; Beecham Research Laboratories Ltd.), 


\section{Penicillinase distribution in a bacterial population}

which is a poor substrate for the enzyme and behaves as a competitive inhibitor when mixed with benzylpenicillin, to the benzylpenicillin solution to $4 \mathrm{mg}$. $/ \mathrm{ml}$. This mixed substrate solution was used instead of the benzylpenicillin solution in the reaction mixture. The $K_{m}$ for Bacillus licheniformis strain 749 penicillinase, measured by the micro-iodometric method of Novick (1962), was found to be $6 \cdot 7 \times 10^{-5} \mathrm{M}$ for benzylpenicillin, and the $K_{i}$ for methicillin was found to be $1.9 \times 10^{-6}$ M. This value of the $K_{m}$ is about $36 \%$ of that found by Manson, Pollock \& Tridgell (1954); the method used by these authors has been found to give higher values than other methods (Dr M. R. Pollock, private communication). With the mixed substrate solution in the reaction mixture, the observed enzymic activity was about $5 \%$ of the activity with benzylpenicillin alone. The maximum velocity of hydrolysis of methicillin was about $0 \cdot 6 \%$ of that of benzylpenicillin, and the hydrolysis of the methicillin in the mixed substrate solution by penicillinase was negligible as compared with that of benzylpenicillin under the experimental conditions. The precise degree of inhibition was confirmed for each reaction mixture by testing a known amount of soluble penicillinase with the mixed substrate solution diluted tenfold with $0 \cdot 1 \mathrm{M}-\mathrm{K}$ phosphate buffer $(\mathrm{pH} \mathrm{7 \cdot 2)}$. The tenfold dilution brought the final concentrations of the penicillins to those found in the reaction mixture after the suspension of organisms had been added. Penicillinase solutions of known concentration were used to calibrate the response of the mixed substrate reaction mixture in the microassay; the calculated enzyme activity was multiplied by the factor determined in the bulk mixed substrate assay to correct for the inhibition of the enzyme reaction.

\section{RESULTS}

\section{The penicillinase from Bacillus lichenifornis strain 749}

The amount of penicillinase in an individual organism is most simply expressed as the number of molecules of enzyme; one molecule of penicillinase must represent the fundamental unit of enzyme activity, and the use of these units aids the interpretation of results in terms of possible biochemical mechanisms. The molecular activity of the purified enzyme from Bacillus licheniformis strain 749/c (Dr M. R. Pollock, private communication) is close to that of crystalline penicillinase from B. cereus strain 569 (Kogut et al. 1956). One molecule of this penicillinase is equivalent to about $1.5 \times 10^{-11}$ units of penicillinase activity, the unit being defined as that amount of enzyme which hydrolyses $1 \mu$ mole benzylpenicillin/hr at $\mathrm{pH} 7 \cdot 0$ and $30^{\circ}$ in the presence of enzyme-saturating concentrations of benzylpenicillin. The experimental results given here are expressed as molecules of enzyme/single organism, by using this conversion factor.

\section{Mean residence time of penicillinase molecules in the bacilli}

The mean residence time was determined for the penicillinase molecules present in the bacilli in uninduced, induced and constitutive populations. In all three populations $68 \%$ of the total enzyme was found attached to the bacilli, and $32 \%$ was found free in the medium in the steady state. The mean residence time was therefore calculated (by equation (2)) to be $\mathbf{1 \cdot 6}$ doubling times for the enzyme in these populations. In the steady-state growth experiments, the differential rate of formation of penicillinase with respect to bacterial growth is proportional to the specific 


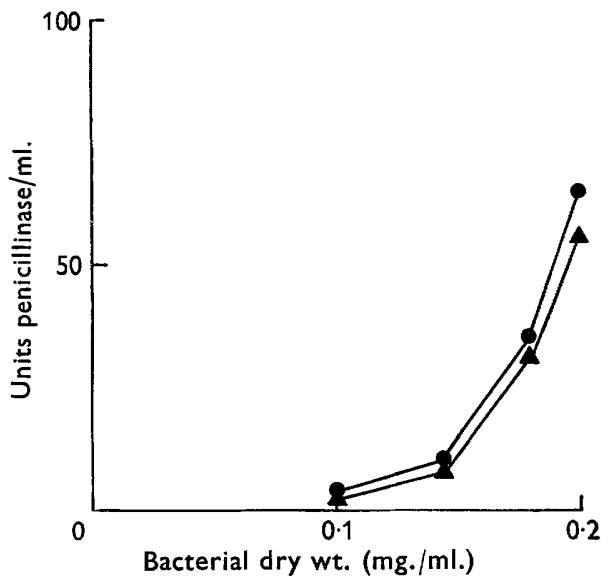

Fig. 1

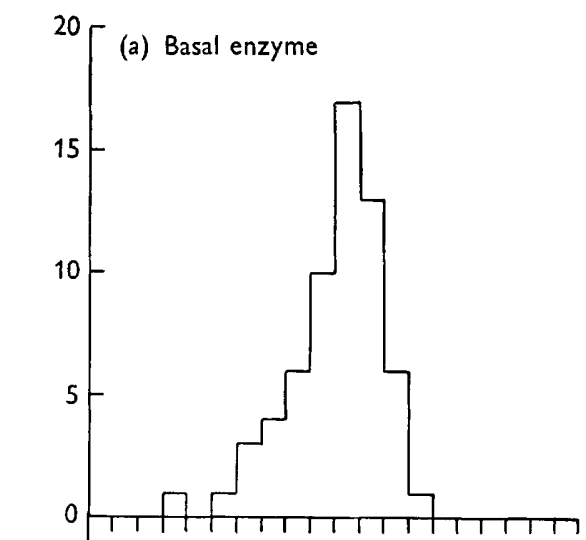

(b) Induced enzyme

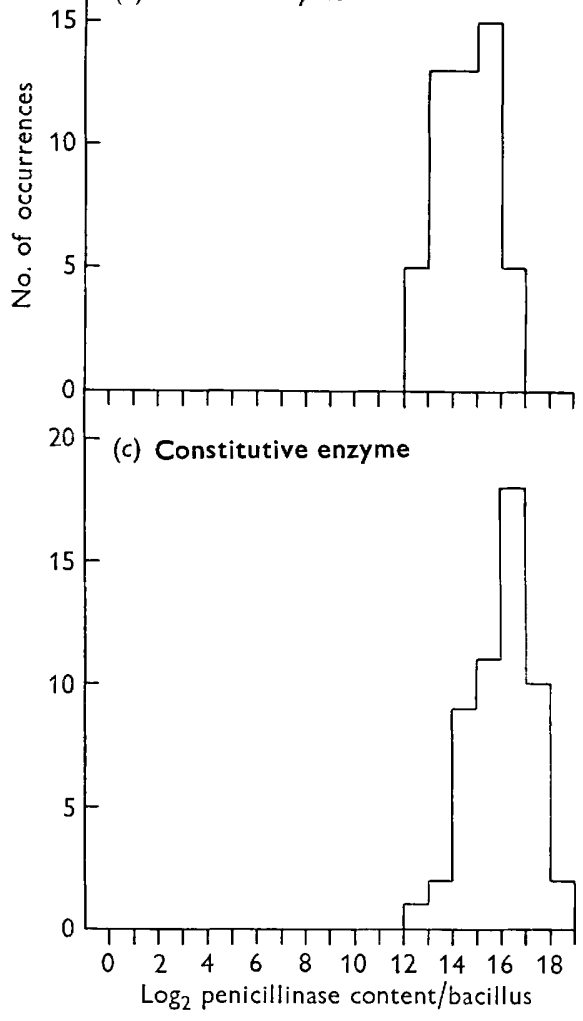

Fig. 2

Fig. 1. Course of penicillinase formation by Bacillus licheniformis strain 749 after induction with $5 \mu \mathrm{g}$. cephalosporin $\mathrm{C} / \mathrm{ml}$. The cephalosporin $\mathrm{C}$ was added to the culture when it contained the equivalent of $0.1 \mathrm{mg}$. dry wt. bacilli $/ \mathrm{ml}$.

Fig. 2. Distributions of penicillinase in $(a)$ uninduced, $(b)$ induced populations of Bacillus licheniformis strain 749 , and in $(c)$ constitutive population of $B$. licheniformis strain $749 / \mathrm{C}$; expressed as the logarithm to the base 2 of the number of penicillinase molecules/bacillus. 
activity in the culture, given by total penicillinase present divided by quantity of bacteria. Total penicillinase is $\mathbf{1} \cdot \mathbf{4} 7$ times the cell-bound enzyme, from the result given above; hence it is possible to calculate enzyme synthesis and loss from the bacteria for one doubling time as follows. If initially in the steady state $a$ bacteria contain $b$ units of penicillinase, there will be a total of $1.47 b$ units of penicillinase in the culture. One doubling time later, there will be $2 a$ bacteria, a total of $2 \cdot 94 b$ units of penicillinase, $2 b$ of which will be cell-bound, since the specific activity of the bacteria remains constant. The amount of penicillinase synthesized will be $1 \cdot 47 b$ units; hence, if no enzyme had been released from the bacteria, they would contain $b+1 \cdot 47 b=2 \cdot 47 b$ units. Thus $0 \cdot 47 b$ units have been released during this period. The course of induction (Fig. 1) shows that the penicillinase formed during one doubling time after induction was predominantly cell-bound, though the free penicillinase (the difference between the curves of the total and the cell-bound enzyme) began to increase towards the end of the experiment. This suggested that the mechanism of release of penicillinase, which functions in the three populations examined in a similar manner, operated principally on the older penicillinase present, and that release might be achieved only after a period of maturation of the enzyme after formation. A simple assumption that might be made was that the enzyme was released sequentially from the bacilli $1 \cdot 6$ doubling times after formation.

\section{The comparative distribution of penicillinase in the uninduced, induced and constitutive populations}

The distributions of penicillinase in the three populations are shown in Fig. 2. The microassays were performed on organisms from exponentially growing cultures of Bacillus licheniformis strain 749 for the uninduced population (63 assays) and the induced population (51 assays), and on organisms from exponentially growing cultures of $\boldsymbol{B}$. licheniformis strain $749 / \mathrm{c}$ for the constitutive population (53 assays). The penicillinase content is expressed as the logarithm to the base 2 of thenumber of molecules present in the organism so that the wide range of results can be accommodated in a single figure. The three populations are clearly distinct, with mean values in the ratios $1: 30: 90$, which compare well with the values found in suspensions of the bacilli. The induced and constitutive populations contain few organisms with less than $8192\left(2^{13}\right)$ molecules of penicillinase, the upper limit reached in the uninduced population. The range of enzyme contents was large in all three populations, being about 2000 -fold in the uninduced population, 32-fold in the induced population and $\mathbf{1 2 8}$-fold in the constitutive population. The induced population does not appear to be a mixture of the uninduced and constitutive populations.

\section{Analysis of the penicillinase distribution in the uninduced population}

The distribution of penicillinase in the uninduced population is shown on an arithmetic scale in Fig. 3. The distribution has a large positive skew; the range extends from almost 0 to 4000 penicillinase molecules/bacillus; the mean value is 940. This value compares closely with the mean penicillinase content/bacillus (1010 molecules) measured in the suspensions of washed organisms used in the 
microassay. Several of the bacilli produceed no change in the light transmission through their assay drops during the period of observation (up to $2 \mathrm{hr}$ in one case). It is not possible to be certain that no penicillinase was present in these organisms, but an upper limit may be set to the penicillinase content as the amount that would have produced the least detectable change over the period of observation. This upper limit for two bacilli was 30 molecules, less than $3 \%$ of the mean value. The highest content measured was four times the mean value. Because of the large range in enzyme contents found, it was necessary to confirm that individual spores of

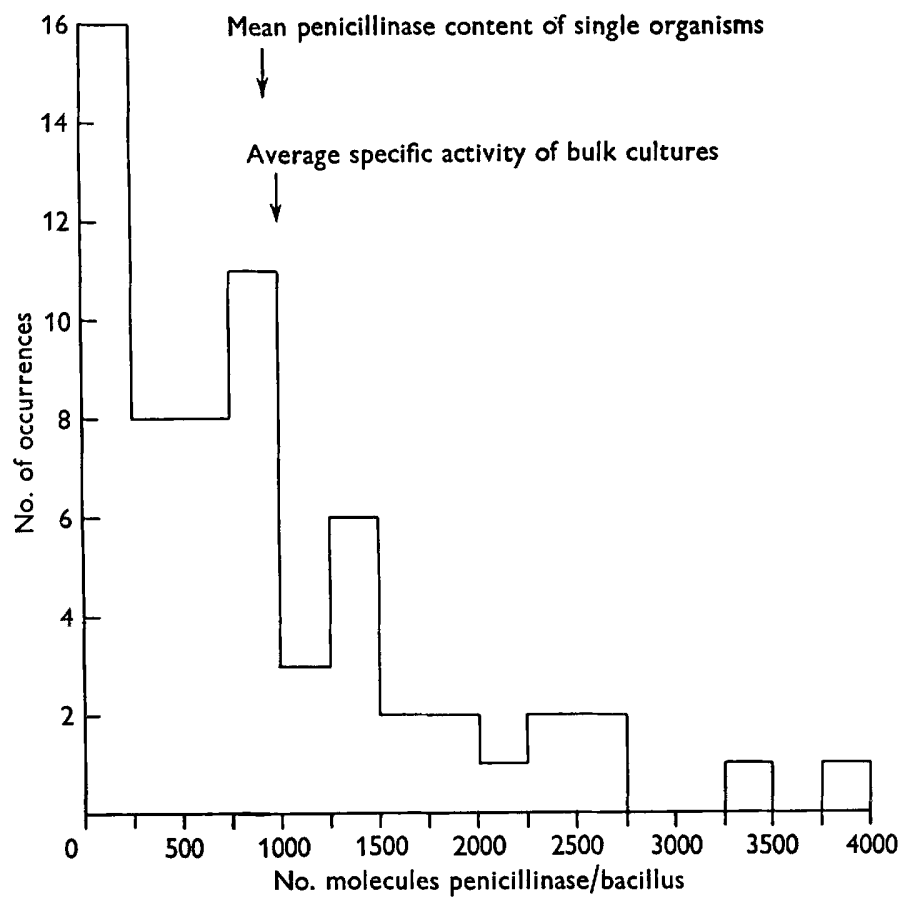

Fig. 3. The distribution of penicillinase in an exponentially growing uninduced population of Bacillus licheniformis strain 749 .

Bacillus licheniformis strain $\mathbf{7 4 9}$ did not give rise to populations of bacilli with widely differing penicillinase contents. In control experiments, therefore, the mean specific penicillinase activity of bacilli in cultures grown from single colony isolates of the main spore stock was measured using the Perret assay technique with about $10^{9}$ washed organisms. The variation found in a number of these isolates (shown in Fig. 4) was similar to the day-to-day variations in specific penicillinase activity measured in the same way in the suspensions of washed bacilli used for the microassay. Since the cultures used to provide these suspensions were grown from large inocula of spores, it was concluded that the spores were genetically homogeneous with respect to the production of penicillinase, the variations arising perhaps from slight changes in the environmental conditions from day to day. The large range of penicillinase contents of single bacilli found could not be explained therefore on the grounds of either genetic or environmental differences between the organisms, but 
must reflect the process of penicillinase production in individual organisms, which, taken in the total population, gives a constant ratio of penicillinase to bacterial dry weight. It was therefore reasonable to treat the sixty-three observations of single organisms as a single distribution for further analysis. This distribution is a property of an exponentially growing culture which should be stable on further increase of the population; i.e. not only is the specific enzyme activity/bacillus constant, but the proportions of the population with any given enzyme content must also remain constant (see Collins \& Richmond, 1962). It is possible to visualize from the logarithmic distribution different patterns of enzyme synthesis and release from the original bacilli which will achieve this stable distribution again after one doubling of the organisms. All the bacilli could be synthesizing some enzyme during the doubling time, since bacilli with very little enzyme content could always have arisen from an asymmetric partition of the enzyme when the parent organisms divided. With any pattern of release and partition, synthesis must have occurred in at least 17 out of the population of 63 bacilli, i.e. $27 \%$ of the population, during the doubling period, so that penicillinase synthesis by an uninduced organism is not a rare event, although the uninduced bacteria produce only about $1 \%$ as much penicillinase as the constitutive bacteria.

Table 1. Comparison of the distribution of basal penicillinase (expressed as groups of 1100 molecules) and the theoretical Poisson distribution

\begin{tabular}{ccc} 
Groups of enzyme & \multicolumn{2}{c}{ No. of occurrences in distribution } \\
\cline { 2 - 3 } molecules/bacillus & Basal enzyme & Poisson distribution \\
0 & 26 & 27 \\
1 & 26 & 23 \\
2 & 9 & 9 \\
3 & 1 & 3 \\
4 & 1 & 1 \\
Total & 63 & 63
\end{tabular}

The average rate of penicillinase synthesis during one doubling period is $\mathbf{1} \cdot \mathbf{4} 7$ times the average content, that is, 1380 molecules. The highest content measured was 3900 molecules; if one doubling time later two bacteria have this content (to maintain the distribution constant in proportion) a minimum synthesis of 3900 molecules must occur in the bacterium already containing this amount, assuming no enzyme to be lost. Therefore, penicillinase synthesis must occur in a small proportion of the population at least at this rate, which is $\mathbf{2 \cdot 8}$ times the average rate. There is therefore evidence in the distribution of a range of rates of penicillinase synthesis in the bacilli.

It is also possible from the distribution to deduce whether or not penicillinase molecules are synthesized as independent random events. If the molecules are synthesized as independent events, the distribution of enzyme in the population should be a Poisson distribution when the content is expressed as the number of molecules present. If there is any association in penicillinase production, i.e. a tendency for enzyme molecules to be produced in groups, the distribution will be a Poisson distribution only when expressed in terms of the total activity of such a group of penicillinase molecules. The penicillinase distribution in the uninduced 
population can be expressed as a Poisson distribution (whose mean is equal to the variance) only when the penicillinase content is expressed as multiples of 1100 molecules. The Poisson distribution arises when the occurrence of an event in an individual in a large population does not affect the probability that a similar event will occur again in that individual. Thus the penicillinase distribution found might arise if the penicillinase gene were functioning as a source of information for the enzyme infrequently and randomly, but, each time it functioned, 1100 molecules of penicillinase were synthesized. The group of 1100 penicillinase molecules would then represent the output of either a single enzyme-forming site, or of a number of such sites resulting from the copies of the penicillinase gene made during its period of activity. The distribution ('Table 1) shows that the bacteria contain from 0 to 4 of these groups of 1100 penicillinase molecules, the average content being equal to $0 \cdot 85$ group. The average rate of synthesis is then equal to $1 \cdot 25$ groups of 1100 penicillinase molecules per doubling time.

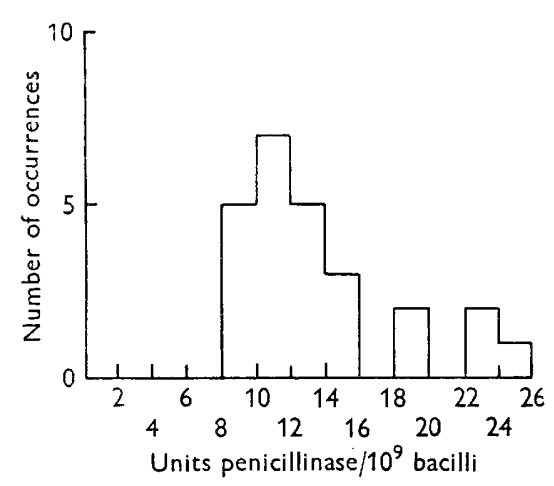

Fig. 4

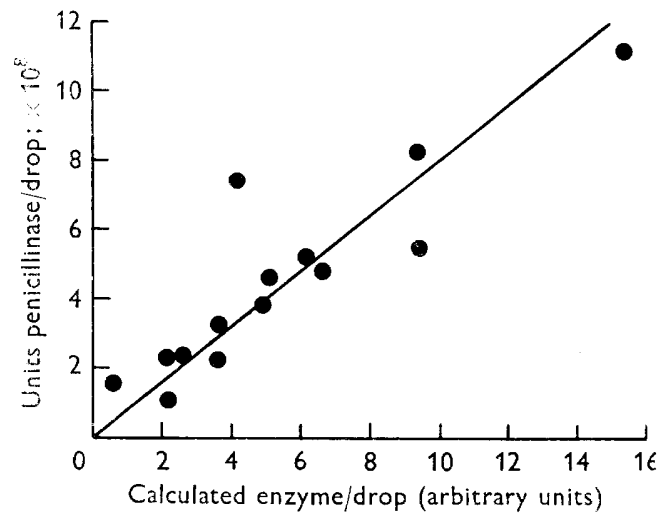

Fig. 5

Fig. 4. Variation in the cell-bound penicillinase activity from different uninduced cultures of Bacillus licheniformis strain 749 .

Fig. 5. Calibration of the assay mixture containing benzylpenicillin $+6-(2,6$-dimethoxybenzamido)-penicillanic acid, by using soluble penicillinase. This mixture was used to assay the penicillinase content of induced and constitutive bacilli.

\section{The penicillinase distribution in the population after induction}

This penicillinase distribution was measured using the modified assay mixture containing methicillin to inhibit the enzymic reaction to a convenient rate. The calibration of the modified assay mixture was made by using soluble penicillinase from Bacillus licheniformis strains 749 and 749/c. A linear relation between the amount of enzyme in a microdrop and the photometric units calculated from the transmission of the microdrop was obtained over a wide range of enzyme concentration (Fig. 5); the errors were similar to those found in the calibration of the microassay when using benzylpenicillin alone with much lower concentrations of the soluble penicillinase (Collins et al. 1964).

The distribution of the cell-bound penicillinase produced by Bacillus licheniformis strain 749 was measured in cultures which had grown for 1 doubling time after induction with cephalosporin $\mathrm{C}(5 \mu \mathrm{g} . / \mathrm{ml})$. After 1 doubling time most of the 
penicillinase synthesized in response to the inducer was still bound to the cells (Fig. 1), while most of the original bacteria had divided only once. Thus the distribution should reflect primarily the response of the original bacteria to the inducer before the processes of enzyme release and partition at division dominate the picture. The distribution is plotted logarithmically in Fig. 2, and arithmetically in Fig. 6. There is a positive skew in the latter, the range being from 4000 to 90,000 molecules of penicillinase/bacillus. The mean content was 30,400 molecules, compared to average specific activity of $\mathbf{2 5 , 5 0 0}$ molecules/bacillus found in washed suspensions from bulk cultures.

The penicillinase distribution in this population represents an intermediate stage between the distribution on the uninduced population and the distribution after prolonged induction. Hence the pattern will not be stable as the population continues growing. It can be seen in Fig. 2 that the distributions of the uninduced and induced populations just overlap, but it is clearly unlikely that any of the bacilli induced with cephalosporin $\mathrm{C}$ have failed to respond by increasing the rate of synthesis of penicillinase. In fact, a bacterium which would have synthesized 1380 molecules of penicillinase, the average amount in one doubling time without induction, has synthesized about 60,000 molecules of penicillinase (the average content of two of the induced bacteria) in this period after induction. As the penicillinase content in the induced population reaches 89,500 molecules, some bacilli have synthesized penicillinase considerably faster than the average rate. A lower limit for the rate of synthesis is similarly twice the lowest content, or 9910 molecules, though this may be less than the smallest response in the population if enzyme partition at cell division were uneven.

\section{The distribution of penicillinase in the constitutive population}

The mixed substrate assay system was used to examine the penicillinase distribution in the constitutive strain of Bacillus licheniformis, $749 / \mathrm{c}$. The distribution is slown logarithmically in Fig. 2 , and arithmetically in Fig. $\%$, where it has a positive skew. The distribution ranges from 4500 to 360,000 molecules/bacillus. The mean content was 84,500 molecules, about 90 times the mean content of uninduced bacilli. As a control, twenty-four single-colony isolates of the constitutive strain were grown under the usual conditions and the cell-bound penicillinase measured. The specific activities of washed suspensions showed only a $2: 1$ range, confirming the homogeneity of the strain with respect to its penicillinase production.

The constitutive population should have a penicillinase distribution which is stable, i.e. unchanging with growth of the culture. It may be analysed in a similar manner to that of the uninduced population. The most economical arrangement of penicillinase release and synthesis which retains the shape of the distribution after growth of the population for one doubling time requires at least $18(34 \%)$ of the bacilli to synthesize at least 2048 molecules of penicillinase. In order to maintain a constant proportion of the population with a penicillinase content of 360,000 molecules synthesis should also occur at least at the rate equal to 360,000 molecules/ doubling time in a small proportion of the population. The mean rate of synthesis of penicillinase is $1 \cdot 47$ times the average content, or 124,200 molecules per doubling time. The higher rate is $\mathbf{2 . 9}$ times the average rate, similar to the value found for the same ratio in the induced population. The analysis of the penicillinase distribution 
in the constitutive population as a Poisson distribution suggests that penicillinase molecules are synthesized in large groups of about 55,000 molecules, the bacilli containing from 0 to 7 of these groups (average 1.53). These large groups of penicillinase molecules are the equivalent of $\mathbf{5 0}$ of the groups of penicillinase molecules found in the penicillinase distribution of the uninduced population. If the formation of a constitutive mutant involves a change in the DNA which affects the rate of synthesis but not the properties of the messenger-RNA molecule (Jacob \& Monod, 1961), the large group of penicillinase molecules may represent the product of the messenger-RNA molecules produced by one constitutive penicillinase gene between its formation and replication.

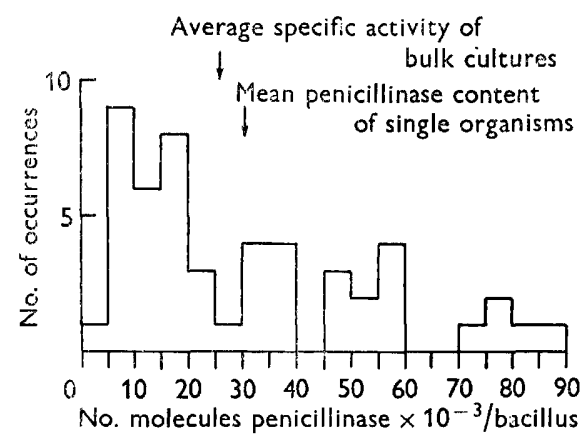

Fig. 6

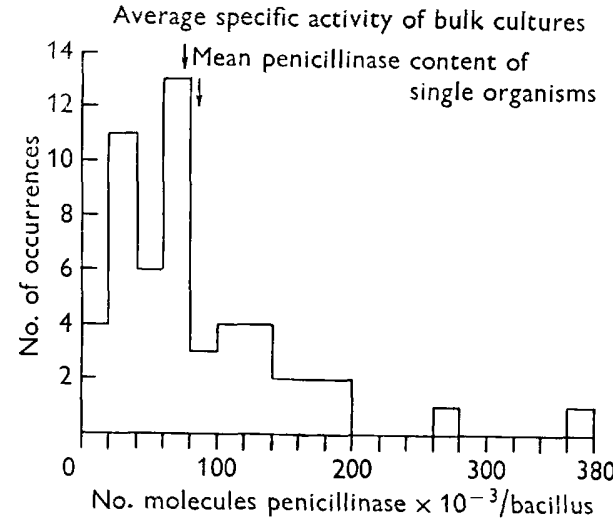

Fig. 7

Fig. 6. The distribution of penicillinase in an exponentially growing population of Bacillus licheniformis strain 749 . One doubling time after induction with $5 \mu \mathrm{g}$. cephalosporin $\mathbf{c} / \mathrm{ml}$.

Fig. 7. The distribution of penicillinase in an exponentially growing population of Bacillus licheniformis strain $749 / \mathrm{c}$.

If, moreover, the penicillinase gene in this constitutive mutant has lost a specific controlling substance (a genetic repressor) (Jacob \& Monod, 1961), then every such gene should produce messengers and at least one large group of 55,000 penicillinase molecules should be found in a bacillus when it divides. The presence of bacilli (12 out of 53, i.e. $23 \%$ ) containing half this amount suggests that penicillinase partition is often uneven; indeed, the lowest content observed was only $8 \%$ of one large group of 55,000 penicillinase molecules, or one-sixth of a half-share. The division of bacilli of the two strains of Bacillus licheniformis, 749 and $749 / \mathrm{c}$, was observed to give two daughter bacilli of nearly equal size by microscopic examination of growing cultures. Highly asymmetric partition of penicillinase might arise if the enzyme were not freely diffusible within the cell cytoplasm, but distributed nonrandomly in association with some structural elements within the bacillus. That this is true is suggested by the findings of Dr J. O. Lampen (personal communication) about the location of the cell-bound penicillinase in this organism and of Kushner \& Pollock (1961) about the cell-bound penicillinase in $\boldsymbol{B}$. licheniformis strain 6346, which they concluded was largely, if not entirely, bound to insoluble cell structures probably associated with the cell envelope. If penicillinase molecules were bound, 


\section{Penicillinase distribution in a bacterial population}

for example, into the cell membrane, both the unequal partition of the enzyme at division and the lag before release of the penicillinase from the bacilli could be explained. Thus extension of the cell membrane during growth might be associated with transfer of bound protein molecules within the permeability barrier of the bacillus to the outside, from which they could be released in a soluble form into the medium.

\section{DISCUSSION}

The penicillinase system of Bacillus licheniformis strains 749 and $749 / \mathrm{c}$ was chosen for the study of enzyme distribution within exponentially growing populations of bacilli because it was possible to obtain populations with a wide range of specific cell-bound penicillinase activities, and in different phases of expression of the same gene (i.e. in the uninduced and induced populations). Further, the sensitivity of the microphotometric method (Collins et al. 1964) was sufficient to measure the penicillinase distribution in the population of uninduced bacilli in detail, but could be decreased (by use of the competitive inhibitor methicillin) so that the higher penicillinase contents found in the bacilli of the induced and constitutive populations could be measured by the same technique.

The cell-bound penicillinase has been shown to consist mainly of the more recently synthesized enzyme molecules which have a mean residence time on the bacilli of $\mathbf{1} \cdot \mathbf{6}$ doubling times. This time was the same in the uninduced, induced and constitutive populations, which had average penicillinase contents in the ratio $1: 30: 90$. The mechanism of enzyme release appeared to be the same in these three cases, and it might be related to the pattern of events which occurs during the bacterial division cycle, particularly since the cell-bound penicillinase was largely associated with insoluble cell structures (Dr J. O. Lampen; personal communication). Since the more recently synthesized penicillinase was attached to the bacilli, the enzyme distribution reflected mainly the recent activity of the penicillinase genes in the population. In individual bacilli, the penicillinase content is determined by the amounts of enzyme inherited, synthesized and lost since the bacillus was formed. While specific figures cannot be given for the behaviour of any individual bacillus, it was possible to deduce information about the rates and variation in rates of synthesis of penicillinase from the distributions of uninduced and constitutive populations, because these distributions were stable patterns unchanging with further growth. In both these populations there must be a range of rates of penicillinase formation at least up to three times the average rate. However, these populations differ in a significant manner.

In the uninduced population forming penicillinase at about $1 \%$ of the rate reached in the constitutive population, it could be shown that penicillinase synthesis was not a rare event, so that the penicillinase genes are capable of functioning at rates less than the constitutive rate during one doubling time. The penicillinase is distributed within the bacterial population as if it were distributed into bacilli at random in groups of 1100 molecules. If the penicillinase gene can be expressed only in 'quanta' of 1100 penicillinase molecules, the synthetic ability of one copy of the penicillinase gene may in fact be about that number of molecules of penicillinase. It is in fact likely that this is the case, since, if the $\mathbf{1 1 0 0}$ molecules were the product of more than one copy of the gene, the number of copies formed by the 
gene should vary in a random fashion, and the distribution would be of the double Poisson type. Fitting a double Poisson distribution to the observed data scarcely alters the number of penicillinase molecules in the group, so that either the original suggestion is correct, or when the gene functions a predetermined number of copies are always made-clearly a more complex explanation.

There are other features of the penicillinase system in Bacillus licheniformis strain 749 that are consistent with the idea that the enzyme-forming site has a considerable lifetime, and might make a large number of penicillinase molecules. The lag (about $60 \mathrm{~min}$.) that occurs upon induction before a constant differential rate of penicillinase synthesis is attained, and the continued production of penicillinase in the absence of any free inducer for up to $2 \mathrm{hr}$, might both reflect the presence of long-lived enzyme-forming sites. Thus, in uninduced bacilli, the formation of penicillinase appears to follow the production of one copy of the penicillinase gene, this copy being produced as a random event about once per gene per doubling time (the exact frequency depending upon the average number of penicillinase genes/bacillus). With such a low rate of functioning of the penicillinase gene, it is possible that the gene might be copied into messenger-RNA molecules not entirely at random during its lifetime, but perhaps with greater probability soon after it had been formed, if control were normally exercised by a specific repressor molecule. Thus a new penicillinase gene may be copied as soon as it is completed, before a repressor molecule is attached.

In the constitutive population, penicillinase appeared distributed in the bacilli in large groups of $\mathbf{5 5 , 0 0 0}$ molecules -50 times the number produced by one copy of the gene. These large groups ( $0-7$ per bacillus) may be the product of one constitutive gene, during its lifetime. The number of large groups should then be related to the number of functional penicillinase genes present in the bacillus. If the constitutive penicillinase gene is of the type proposed by Jacob \& Monod (1961), functioning in the absence of a normal repressor, every bacillus should contain at least half a large group of penicillinase molecules. The large number of exceptions suggest uneven partition of penicillinase at division. The cell-bound enzyme is known to be associated with insoluble (probably membranous) particles, which, if part of the cell envelope, would maintain their gross spatial organization as the cells grew and the membrane extended. To account for the non-random distribution on these structures, a free cytoplasmic stage of the penicillinase molecule is rendered unlikely, unless specific receptor sites are also non-randomly spread in the envelope. The high penicillinase content of the constitutive strain makes this receptor hypothesis difficult to maintain, since the penicillinase molecules could cover a substantial portion of the cell envelope as a monomolecular layer. An alternative hypothesis is that penicillinase molecules are synthesized at or near the cell envelope, the new molecules being absorbed into the envelope immediately after production. If the enzyme-forming sites were also immobilized in a similar manner, the enzymeforming sites produced by one penicillinase gene might all be held in a small region near the membrane of the cell, and the group of penicillinase molecules produced might have as a result a spatial as well as a statistical association.

In the induced population, the distribution of penicillinase shows that the original bacilli treated with cephalosporin $\mathbf{C}$ have all responded to the stimulus and produced more penicillinase than bacilli in the uninduced population, though the range of 
response is not defined well. The average synthesis $(60,000$ molecules) was half the average rate in a bacillus of the constitutive strain.

The induction process (Fig. 1) accelerates gradually, and the slow start may be caused in a number of ways, e.g. by delay in the inducer reaching its operative site, delay in the repressed gene becoming functional after the inducer has acted, or delay while the new penicillinase-forming sites begin to operate. It is hoped to investigate further the mechanism of control of the penicillinase gene in this organism under other physiological conditions.

I wish to thank Dr M. R. Pollock, F.R.S., for his patience and encouragement during this work, Miss M. V. Mussett and Dr P. H. A. Sneath for advice about population statistics, Dr J. Mandelstam for helpful discussions and Mr P. Thompson for his technical assistance in the microassays. I am grateful to Dr A. H. Campbell (Glaxo Research Ltd., Sefton Park, Stoke Poges) for a generous gift of cephalosporin $\mathrm{C}$.

\section{REFERENCES}

BEnzer, S. (1953). Induced synthesis of enzymes in bacteria analyzed at the cellular level. Biochim. biophys. Acta, 11, 383.

Conn, M. \& Honibata, K. (1959 $a$ ). Inhibition by glucose of the induced synthesis of the $\beta$ galactoside-enzyme system of Escherichia coli. Analysis of maintenance. J. Bact. 78, 601 .

Conn, M. \& Horibata, K. (1959 b). Analysis of the differentiation and of the heterogeneity within a population of Escherichia coli undergoing induced $\beta$-galactosidase synthesis. J. Bact. 78, 613.

Collins, J. F. (1962). Estimation of penieillinase in single bacterial cells. Biochem. $J$. 82,28 P.

Collins, J. F. \& Kornberg, H. L. (1960). The metabolism of $\mathrm{C}_{2}$ compounds in microorganisms. Biochem. J. 77, 430.

Collins, J. F., Mason, D. B. \& Perkins, W. J. (1964). A microphotometric method for the estimation of penicillinase in single bacterial cells. J. gen. Microbiol. 34, 353.

Cortuns, J. F. \& Richmond, M. H. (1962). Rate of growth of Bacillus cereus between divisions. J. gen. Microbiol. 28, 15.

Kogut, M., Pollock, M. R. \& Tridgell, E. J. (1956). Purification of penicillin-induced penicillinase of Bacillus cereus NRRL 569 ; a comparison of its properties with those of a similarly purified penicillinase produced spontaneously by a constitutive mutant. Biochem. J. 62, 391.

Kushner, D. J. (1960). An immunological study of Bacillus subtilis penicillinases. J. gen. Microbiol. 23, 381.

Kushner, D. J. \& Pollock, M. R. (1961). The location of cell-bound penicillinase in Bacillus subtilis. J. gen. Microbiol. 26, 255.

$J_{\text {AсOB, }}$ F. \& MONOD, J. (1961). Genetic regulatory mechanisms in the synthesis of proteins. J. molec. Biol. 3, 318.

Mansox, E. E., Pollock, M. R. \& Tridgel., E. J. (1954). A comparison of the properties of penicillinase produced by Bacillus subtilis and Bacillus cereus with and without addition of penicillin. J. gen. Microbiol. 11, 493.

Novick, A. \& Weiner, M. (1957). Enzyme induction as an all-or-none phenomenon. Proc. nat. Acad. Sci., Wash. 43, 553.

Novick, R. P. (1962). Micro-iodometric assay for penicillinase. Biochem. J. 83, 236.

Novick, R. P. (1963). Analysis by transduction of mutations affecting penicillinase formation in Staphylococcus aureus. J. gen. Microbiol. 33, 121.

Perret, C. J. (1954). Iodometric assay of penicillinase. Nature, Lond. 174, 1012.

Pollock, M. R. \& Perret, C. J. (1951). 'The relation between the fixation of penicillinsulphur and pencillinase adaptation in B. cereus. Brit. J. exp. Path. 32, 387.

Wright, H. D. (1933). The importance of adequate reduction of peptone in the preparation of media for the Pneumococcus and other organisms. J. Path. Bact. 37, 257. 